\title{
HIDROPONIK SEBAGAI SARANA PEMANFAATAN LAHAN SEMPIT DI DUSUN RANDUBELANG, BANGUNHARJO, SEWON, BANTUL
}

\author{
Oleh: Anang Masduki \\ Mahasiswa KKN Alternatif LVI Unit I.C.1 \\ Universitas Ahmad Dahlan \\ E-mail: anang_masduki@yahoo.com
}

\begin{abstract}
Ringkasan
Sayuran organik merupakan sebutan umum untuk bahan pangan. Terdapat beraneka macam sayuran organik, seperti selada, terong, dan cousin. Bahan pangan yang mengandung banyak antioksidan ini sangat diminati oleh masyarakat baik kalangan menengah ke bawah maupun menengah ke atas. Namun, keterbatasan lahan menjadi salah satu kendala yang dialami masyarakat yang ingin menanam bahan pangan yang satu ini. Melihat masalah tersebut, kami sebagai mahasiswa KKN berusaha semaksimal mungkin untuk memberikan pengetahuan kepada masyarakat tentang cara memanfaatkan lahan sempit agar menjadi lebih bermanfaat. Salah satu program unggulan kami dalam mewujudkan hal tersebut adalah Hidroponik. Teknik yang kami gunakanpun sangat sederhana yaitu teknik aquaponik. Teknik ini sangat tepat digunakan untuk lingkungan rumah yang sempit.
\end{abstract}

Kata kunci: Sayuran Organic, Hidroponik, Akuaponik

\begin{abstract}
Organic vegetables is a common term for foodstuffs. There are various kinds of organic vegetables, such as lettuce, eggplant, and cousin. Foodstuffs that contain lots of antioxidants are very interested by the society. However, the limited land becomes one of the obstacles faced by society who want to grow organic vegetables in their own house. Based on this problem, we as students who is serving to society are try to give knowledge for society about how to use the narrow land to be more useful. One of our great program is Hydroponics. The technique that we use is very simple, that is aquaponic techniques. This technique is very appropriate to use for a narrow home environment.
\end{abstract}

Keywords: Organic Vegetables, Hydroponics, Iaponics

\section{A. PENDAHULUAN}

Sayuran adalah makanan kesukaan masyarakat yang biasanya berdampingan dengan sepiring nasi dan lauk lainnya. Ada juga yang memakannya secara langsung tanpa menggunakan nasi. Banyak sekali jenis sayuran yang biasa dikonsumsi oleh masyarakat seperti, selada, sawi hijau, wortel, bayam, kangkung, dan masih banyak lagi.

Selada sangat efektif untuk menurunkan berat badan karena mengandung zat besi dan magnesium yang berfungsi membantu kerja uretik. Selain itu, selada juga bagus untuk mereka yang menderita batuk dan insomnia, membersihkan darah dan membuang kelebihan lemak dalam tubuh.

Bayam dan Kangkung, kedua sayuran ini banyak mengandung vitamin A, vitamin C, mineral, zat besi, kalsium, dan kalium. Manfaat sayuran ini bagi tubuh adalah untuk menghilangkan berbagai penyakit, seperti asma, kolik, anemia, bronchitis pneumonia, konstipa I, osteoporosis, kelelahan, serta kekurangan kalsium. 
Wortel sangat baik untuk kesehatan mata karena memiliki vitamin A dan betakaroten yang tinggi. Masih banyak lagi manfaat sayuran berwarna orange cerah ini, antara lain: mengobati eksim, mengobati cacingan (cacing kremi), demam, luka bakar, nyeri saat haid, menghaluskan kulit, hingga untuk mengatasi hipertensi. Sawi hijau bermanfaat untuk mencegah kanker, penyakit jantung, hipertensi, dan anemia.

Tidak ada batasan secara ilmiah untuk istilah sayuran. Sayuran-sayuran adalah bagian dari tumbuhan. Ada beberapa jenis sayuran yang berasal dan tumbuh dari tanah tertutup, seperti wortel dan lobak. Terdapat pula sayuran yang berasal dari organ generatif, seperti bunga misalnya kecombrang dan buah misalnya terong, tomat dan kapri. Ada juga biji-bijian, buncis dan kacang merah. Bagian tumbuhan lainnya yang juga dianggap sayuran adalah tongkol jagung (baby corn). Meskipun secara ilmiah bukan tumbuhan, bagian cendawan yang dapat dimakan biasa disebut jamur juga digolongkan sebagai sayuran.

Banyaknya manfaat syuran membuat sayuran menjadi bahan pangan sangat penting dan dibutuhkan oleh manusia. Ada beberapa cara untuk mendapatkan sayuran, seperti dengan membeli atau menanam sendiri. Masyarakat yang memiliki lahan serta kemampuan menanam sangat berpotensial untuk mengahasilkan sayuran sendiri tanpa harus membeli. Kebanyakan orang mungkin berpikir bahwa tanpa lahan yang luas dan cukup, mereka tidak akan bisa untuk menanam sayuran. Terlebih masyarakat yang tinggal di daerah perkotaan, mereka akan sulit menemukan lahan yang luas untuk bertanam. Hal ini disebabkan oleh lahan yang sempit.

Salah satu kondisi serupa, kami temukan di Dusun Randubelang, Bangunharjo, Sewon, Kabupaten Bantul. Rata-rata warga langsung membeli sayur di pasar. Kebanyakan memiliki usaha kecil seperti membuka warung di depan rumah dan membuka usaha cathering. Hampir tidak ada yang menanam sayuran di rumah. Hal ini salah satunya disebabkan oleh lahan yang sempit. Atas dasar lahan yang sempit ini, kelompok kami berinisiatif untuk menawarkan cara menanam sayuran dengan menggunakan hidroponik. Tujuannya untuk memanfaatkan lahan sempit yang dimiliki oleh masyarakat. Selain itu juga bisa menjadi salah satu pilihan masyarakat yang ingin membuka usaha.

\section{B. KERANGKA TEORI}

\section{Pengertian Hidroponik}

Sejak abad ke-16, percobaan tentang ilmu nutrisi dengan mengembangkan metode pertanian hidroponik telah dimulai. Semenjak itu, metode pertanian dengan hightechnology ini menjadi lebih populer dan dikenal di seluruh dunia. Hidroponik berasal dari bahasa Latin hydros yang berarti air dan phonos yang berarti kerja. Arti harfiah dari hidroponik adalah kerja air. Bertanam secara hidroponik kemudian dikenal dengan bertanam tanpa medium tanah (soilless cultivation, soilless culture). Mulanya, orang bertanam dengan metode hidroponik menggunakan wadah yang berisi air yang telah dicampur dengan pupuk mikro maupun makro.

\section{Keunggulan dan Kelemahan Hidroponik Keunggulan}

- Tanaman mudah diperbaharui tanpa tergantung kondisi lahan dan musim. 
Diterbitkan oleh Lembaga Pengabdian kepada Masyarakat

Universitas Ahmad Dahlan Yogyakarta

- Pertumbuhan dan kualitas panen dapat diatur.

- Hemat tenaga kerja.

- Produk bersih dan lebih higienis.

- Hemat air dan pupuk (aman untuk kelestarian lingkungan).

- Masa tanam lebih singkat.

- Biaya operasional murah.

\section{Kelemahan}

- Biaya investasi awal lebih mahal.

- Sangat dipengaruhi oleh konsentrasi dan komposisi pupuk, pH, dan suhu.

\section{Pengertian Akuaponik}

Akuaponik adalah sistem pertanian berkelanjutan yang mengkombinasikan Akuakultur dan Hidroponik dalam lingkungan yang bersifat Simbiosis. Dalam akuakultur yang normal, Ekskresi dari hewan yang dipelihara akan terakumulasi di air dan meningkatkan toksisitas air jika tidak dibuang. Dalam akuaponik, ekskresi hewan diberikan kepada tanaman agar dipecah menjadi Nitrat dan Nitrit melalui Siklus nitrogen, dan dimanfaatkan oleh tanaman sebagai nutrisi. Air kemudian bersirkulasi kembali ke sistem akuakultur.

Karena sistem hidroponik dan akuakultur sangat beragam bentuknya maka sistem akuaponik pun menjadi sangat beragam dalam hal ukuran, kerumitan, tipe makhluk hidup yang ditumbuhkan, dan sebagainya.

\section{METODE PELAKSANAAN}

Untuk mewujudkan apa yang menjadi harapan kami sebagai mahasiswa KKN di Dusun Randubelang, Bangunharjo, Sewon, Bantul, kami memberikan penyuluhan, difusi IPTEK atau pengenalan teknologi, dan praktek langsung. Adapun ringksan pelaksanaan kegiatan beserta jam kerja efektif mahasiswa (JKEM) tersaji pada tabel di bawah ini:

Tabel Metode, Kegiatan, JKEM dan keterlibatan mahasiswa

\begin{tabular}{|c|c|l|c|c|}
\hline No & & \multicolumn{1}{|c|}{ Kegiatan } & JKEM & $\begin{array}{c}\text { Mahasiswa } \\
\text { yang terlibat }\end{array}$ \\
\hline 1 & Penyuluhan & $\begin{array}{l}\text { Mengadakan sosialisasi terhadap warga } \\
\text { Dusun Randubelang, Bangunharjo } \\
\text { mengenai program perintisan dusun } \\
\text { organik }\end{array}$ & $1 \times 150 "$ & 9 \\
\hline 2 & $\begin{array}{c}\text { Pengenalan } \\
\text { teknologi }\end{array}$ & $\begin{array}{l}\text { Mengadakan penyemaian sayuran } \\
\text { Organik serta membuat contoh tanaman } \\
\text { dan media tanam yang digunakan 50" }\end{array}$ & 9 \\
\hline $\begin{array}{l}\text { Pengenalan teknik menanam akuaponik, } \\
\text { perawatan sayuran organik serta } \\
\text { pengolahan limbah sebagai media } \\
\text { tanam }\end{array}$ & $1 \times 150 "$ & 9 \\
\hline
\end{tabular}




\begin{tabular}{|l|l|l|l|l|}
\hline 3 & Praktik & $\begin{array}{l}\text { Perawatan bibit tanaman yang sudah } \\
\text { tumbuh ke media tanam yang lebih } \\
\text { besar }\end{array}$ & 50 & 9 \\
\hline
\end{tabular}

\section{PEMBAHASAN}

1. Definisi Secara Etimologis

Secara Etimologis, Hidroponik diambil dari bahasa Yunani yaitu hydro yang artinya air dan ponos yang artinya daya. Hidroponik juga dikenal dengan sebutan soilless culture yang artinya budidaya tanaman tanpa tanah. Jadi tanaman hidroponik adalah tanaman yang ditanam dengan pemanfaatan air dan tanpa penggunaan tanah sebagai media tanam.

2. Definisi Secara Umum

Pengertian tanaman hidroponik secara umum adalah tanaman yang ditanam dengan memanfaatkan air tanpa menggunakan media tanah, melainkan menekankan pada pemenuhan kebutuhan nutrisi tanaman untuk bisa tumbuh. Jadi tanaman hidroponik tidak ditanam di media tanah melainkan media lain seperti bata merah, rockwool, kerikil, arang sekam dan sebagainya.

3. Pelaksanaan dan hasil

Pada awalnya, kami melakukan sosialisasi kepada warga terkait dengan program yang akan kami jalankan selama melakukan KKN di Dusun Randubelang. Kebanyakan dari masyarakat menanyakan terkait dengan program berkelanjutan yang kami adakan. Dengan penuh keyakinan, kami menjawab hidroponiklah yang menjadi program andalan kami dan Alhamdulillah masyarakat mau menerima program ini.

Setelah itu kami berkonsultasi dengan padukuhan terkait dengan lahan yang dapat kami gunakan sebagai lahan hidroponik. Lahan tersebut berada tepat di sisi selatan Masjid Al-Ikhsan yang merupakan posko KKN kami. Lahan tersebut memenuhi kriteria dalam melakukan hidroponik terutama teknik akuaponik yang kami usungkan.

Kemudian setelah itu kami menghubungi Bapak Soni yang beralamatkan di Dusun Salakan. Beliau adalah pembimbing kami dalam menjalankan program hidroponik.

Dengan bimbingan Bapak Soni, benih yang kami pilih untuk ditanam adalah selada, sawi hijau, terong dan cabai. Sedangkan media yang kami gunakan adalah sekam bakar yang diletakkan di atas nampan kecil yang telah kami lubangi terlebih dahulu. Sekam bakar berguna sebagai media utama dalam penyemaian benih hidroponik sebelum diletakkan di dalam botol akua yang telah kami potongpotong. Proses penyemaian pertama kami lakukan di pekarangan rumah Bapak Soni di Dusun Salakan.

Tibalah waktu yang kami nanti yakni proses penyemaian benih sayuran pada media sekam bakar. Perbandingan antara sekam bakar dengan pupuk kandang yang kami gunakan adalah 1 karung pupuk kandang : 2 karung sekam bakar. Setelah pupuk kandang dan sekam bakar itu tercampur sempurna, kemudian di 
Diterbitkan oleh Lembaga Pengabdian kepada Masyarakat

Universitas Ahmad Dahlan Yogyakarta

masukkan ke dalam nampan yang sudah kami siapkan. Dalam keadaan sekam bakar + pupuk kandang yang lembab benih-benih sayuran kami taburkan dengan merata. Kini tingal menunggu pertumbuhan setiap benih yang kami semai.

Setelah didiamkan di tempat yang lembab, dan tidak terpapar sinar matahari secara langsung, benih-benih sayuran itu mulai pecah dan tumbuh. Namun tidak semua, karena pertumbuhan benih sayuran tergantung jenisnya. Pada percobaan kali ini, benih selada yang pertama kali pecah dan benih cabai yang paling terakhir.

Selang beberapa hari, kami kemudian memindahkan benih-benih sayuran yang sebelumnya di rumah Bapak Soni ke lokasi hidroponik yang sudah kami siapkan sebelumnya. Hal itu kami lakukan agar mempermudah kami dalam melakukan sosialisai kepada masyarakat.

Tibalah saat yang kami nanti, yaitu sosialisai kepada warga terkait dengan proses penanaman sayuran hidroponik mulai dari pemilihan media, benih-benih, pupuk kandang, teknik penyemaian, teknik penanaman, dan proses perawatan. Sosiaisai ini kami lakukan guna memberikan pemahaman kepada masyarakat pemanfaatan lahan sempit dengan metode pertanian hidroponik.

Sosialisasi kami lakukan pada tanggal 24 mei 2017 di dua tempat yaitu masjid dan lokasi hidroponik. Masjid kami gunakan sebagai tempat sosialisasi tentang pemilihan media, sekan, pupuk, dan benih. Sedangkan lokasi hidroponik kami gunakan sebagai tempat sosialisasi teknik penyemaian, teknik penanaman, dan cara perawatan. Alhamdulillah antusias warga dengan program kami ini sangat luar biasa. Bahkan setelah selesai melakukan sosialisasi sebagian besar warga membawa pulang tanaman yang telah kami semai terlebih dahulu.

Pada intinya keterbatasan lahan bukan menjadi kendala kita dalam mengkonsumsi makanan yang sehat terutama sayuran. Oleh karena itu marilah kita bersama-sama memanfaatkan lahan-lahan kosong dan sempit dengan membuat tanaman hidroponik demi terpenuhinya gizi bagi tubuh.

Gambar 1: Proses penyamaian bibit sayuran ke media

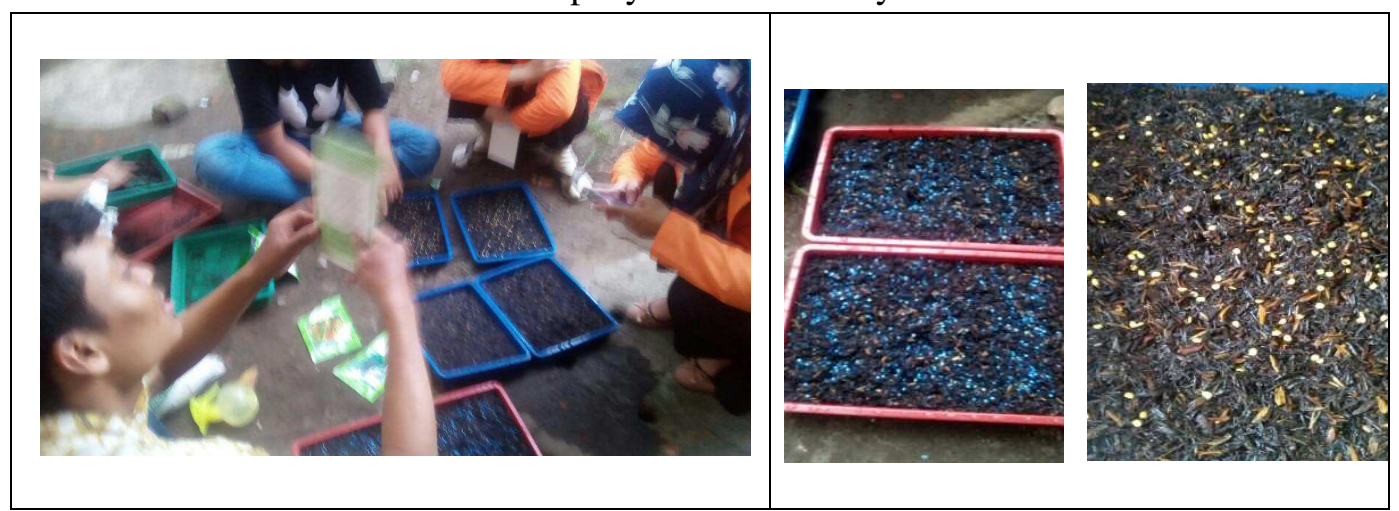

Gambar 2: Sosialisasi pemilihan media, sekan, pupuk, dan benih 


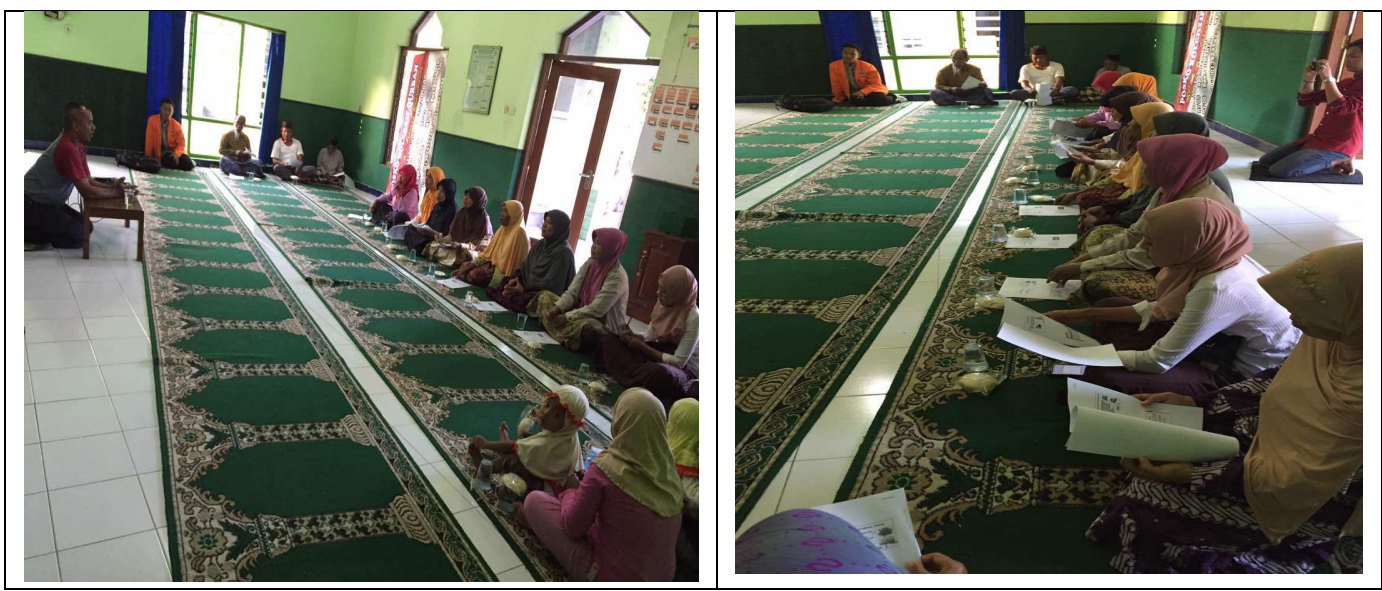

Gambar 3: Sosialisasi kepada warga tentang cara penyemaian, perawatan, dan penanaman

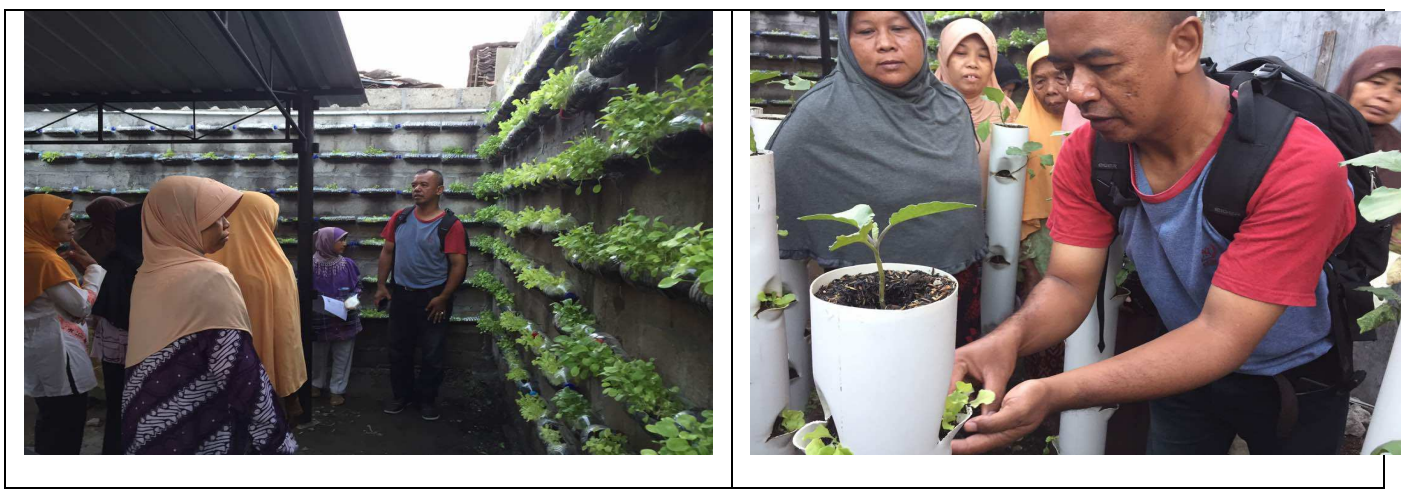

Gambar 4: Penyerahan secara simbolis bibit sayuran hidroponik dari mahasiswa KKN kepada Masyarakat.

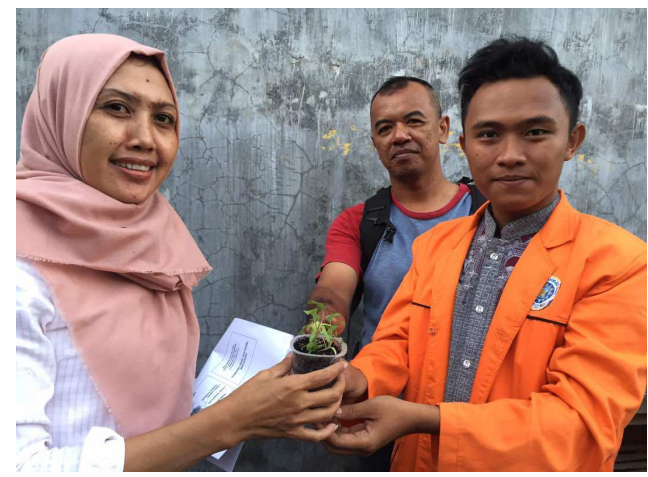

\section{E. KESIMPULAN}

Sayuran merupakan salah satu bahan pangan yang kandungannya sangat diperlukan bagi kesehatan tubuh. Oleh karena itu, kami sebagai mahasiswa KKN berusaha dengan semaksimal mungkin untuk menjalankan program Hidroponik sebagai salah satu upaya kami dalam memberdayakan masyarakat terutama dalam hal bercocok tanam di lahan sempit.

Kami berharap program Hidroponik ini menjadi salah satu program yang dapat dilanjutkan oleh masyarakat di Dusun Randubelang sehingga kebutuhan masyarakat akan 
Diterbitkan oleh Lembaga Pengabdian kepada Masyarakat

Universitas Ahmad Dahlan Yogyakarta

sayur - sayuran dapat terpenuhi dengan maksimal. Selain itu semoga program ini bisa menjadi salah satu pilihan warga yang ingin membuka usaha di tempat tinggalnya.

\section{F. SARAN}

Mengingat pentingnya sayuran bagi kesehatan manusia, kami sangat mengharapkan dukungan dari masyarakat terutama remaja terkait dengan keberlangsungan program Hidroponik yang nantinya dikembangkan oleh masyarakat. lahan-lahan sempit yang dimiliki masyarakat sangat bisa dijadikan potensi, salah satunya melalui pertanian hidroponik. Semoga benih yang telah disemai dapat bermanfaat dan dapat dijaga dengan baik.

\section{DAFTAR PUSTAKA}

http://berkebun.web.id/pengertian-tanaman-hidroponik-adalah/ [diakses pada 18 juli 2017 pukul 22.50]

http://cookshabit.com/read-articles/manfaat-sayur-sayuran-bagi-tubuh-manusia/15 [diakses pada 18 juli 2017 pukul 22.30]

https://id.wikipedia.org/wiki/Sayuran [diakses pada 18 juli 2017 pukul 22.22]

https://id.wikipedia.org/wiki/Akuaponik [diakses pada tanggal 19 juli 2017 pukul 02.15] http://berkebun.web.id/pengertian-tanaman-hidroponik-adalah/ [diakses pada 18 juli 2017 pukul 22.47] 
